\title{
Building a Smart E-Portfolio Platform for Optimal E-Learning Objects Acquisition
}

\author{
Chih-Kun Ke, ${ }^{1}$ Kai-Ping Liu, ${ }^{2}$ and Wen-Chin Chen $^{3}$ \\ ${ }^{1}$ Department of Information Management, National Taichung University of Science and Technology, No. 129, \\ Section 3, Sanmin Road, Taichung 404, Taiwan \\ ${ }^{2}$ Ph. D. Program of Technology Management, Chung Hua University, No. 707, Section 2, Wufu Road, Hsinchu 300, Taiwan \\ ${ }^{3}$ Department of Industrial Management, Chung Hua University, No. 707, Section 2, Wufu Road, Hsinchu 300, Taiwan
}

Correspondence should be addressed to Kai-Ping Liu; lkp085@teamail.ltu.edu.tw

Received 2 July 2013; Accepted 30 September 2013

Academic Editor: Yi-Chung Hu

Copyright (C) 2013 Chih-Kun Ke et al. This is an open access article distributed under the Creative Commons Attribution License, which permits unrestricted use, distribution, and reproduction in any medium, provided the original work is properly cited.

In modern education, an e-portfolio platform helps students in acquiring e-learning objects in a learning activity. Quality is an important consideration in evaluating the desirable e-learning object. Finding a means of determining a high quality e-learning object from a large number of candidate e-learning objects is an important requirement. To assist student learning in a modern e-portfolio platform, this work proposed an optimal selection approach determining a reasonable e-learning object from various candidate e-learning objects. An optimal selection approach which uses advanced information techniques is proposed. Each elearning object undergoes a formalization process. An Information Retrieval (IR) technique extracts and analyses key concepts from the student's previous learning contexts. A context-based utility model computes the expected utility values of various elearning objects based on the extracted key concepts. The expected utility values of e-learning objects are used in a multicriteria decision analysis to determine the optimal selection order of the candidate e-learning objects. The main contribution of this work is the demonstration of an effective e-learning object selection method which is easy to implement within an e-portfolio platform and which makes it smarter.

\section{Introduction}

Effective learning is always a key consideration in compulsory education. Acquiring high quality e-learning objects to assist a student in a learning activity is an important requirement. E-portfolio is a modern platform constructed for students in an educational environment $[1,2]$. In a comprehensive learning activity, students record learning context information, such as credits, score, and reports, in an e-portfolio platform. In addition, an e-portfolio platform helps students in acquiring official e-learning objects, that is, slides, exercises, videos, voice files, and so forth. Quality is an important consideration in evaluating the desirable e-learning object for a specific learning activity. A smart e-portfolio platform is required to support high quality e-learning objects for students' effective learning [3-5].

In a learning activity, student feedback on an evaluation process can be represented as a utility model [6] reflecting the satisfaction a student obtains from choosing a reasonable e-learning object. The student provides a utility model before committing to an e-learning object; context information [7] in the learning activity provides rich clues for e-learning object acquisition. Based on the context information of a learning activity, uncovering hidden knowledge is important. Therefore, context information analysis can quantify all the influences of the various factors and their relationships in order to consolidate a utility model [8]. The student's contextbased utility model can be applied to monitor context information, in order to evaluate the e-learning object's quality. The student will obtain the expected utility value of the issue of interest when choosing an e-learning object.

Because there are various issues of interest, selecting a reasonable e-learning object from a large number of candidate e-learning objects requires a multicriteria decision analysis. A multicriteria decision analysis is concerned with structuring and solving decision and planning problems involving 
multiple criteria [9]. Each specific issue of interest in the context-based utility model is considered as a criterion. The expected utility value of the issue of interest is shown as the criterion's evaluating value. According to a learning activity and students' learning context, several criteria's evaluating values need to be analyzed in order to determine which elearning object is a reasonable one.

This paper explores the context of a learning activity and uses a selection approach for candidate e-learning objects in order to assist the student in acquiring a reasonable elearning object. First, each e-learning object undergoes a formalization process. Moreover, the proposed system employs Information Retrieval (IR) techniques to extract the key concepts of relevant information necessary to handle a specific learning activity. The extracted key concepts form a learning activity profile that models the information needs of students for handling e-learning objects in certain contexts. A contextbased utility model explores the learning activity's context information in order to obtain the candidate e-learning objects' actual expected utility values. Then, a multicriteria decision analysis uses the actual expected utility values to determine the optimal selection order of the candidate elearning objects. A fuzzy weight model is used to consolidate the multicriteria decision analysis method. Finally, the selection order is considered as reasonable decision-making knowledge for the student to optimally select a reasonable e-learning object. In this paper, an experiment is conducted to demonstrate that the selection approach is effective. The main contribution of this work is the demonstration of an effective solution-selecting method which is easy to implement, in order to build a smart e-portfolio platform.

The remainder of this paper is organized as follows. Section 2 reviews related works on e-portfolio and learning contexts, the context-based utility model, and multicriteria decision analysis. Section 3 introduces the proposed optimal e-learning object selection method for building a smart e-portfolio platform. Section 4 uses a specific case to illustrate the steps of an optimal selection approach. The prototype eportfolio platform, experiments, and relevant discussions are shown in Section 5. Finally, in Section 6, conclusions are presented.

\section{Related Works}

The related literature covers the e-portfolio platform and learning contexts, the context-based utility model, and multicriteria decision analysis techniques.

2.1. E-Portfolio Platform and Learning Context. Originally, portfolios presented the best works of literature and art as evidence for showing job and personal achievements. Until 1980 , it was used in the education domain and transformed into digital format e-portfolio by Information Technology, for example, voice, image, text, and multimedia; it was not restricted by computer media type. In modern education, the e-portfolio platform is built for students in an educational environment. Students construct and access personal e-portfolios in the e-portfolio platform to review their selflearning processes $[1,2]$. An e-portfolio platform also assists the teacher in providing a modified teaching model for the student to facilitate effective learning [10, 11]. A smart e-portfolio platform will facilitate student acquisition of high quality e-learning objects [3-5].

According to the definitions [7], context includes the location of the user, the people's identities, and objects around the user, and the devices interact with the user. In other words, context is any information that characterizes the situation of an entity, where the entity can be a user, place, service, or service relevant objects [12]. A learning activity is what a student does in terms of learning in a specific domain during a period of time. A learning activity is considered an entity; we can characterize its relevant context information, including and the environments, credits, scores, reports, and official and comprehensive e-learning objects. By tracking a learning activity, a student's learning context provides rich clues for object selection. The learning context is composed of a series of learning tasks. This may involve several semesters and academic years. The student's learning context may include not only official tasks (e.g., courses) but also comprehensive tasks (e.g., practical training, license testing, and science research tasks). These different learning tasks enrich a student's learning context [8]. Therefore, constructing a smart e-portfolio platform for determining a reasonable e-learning object that will enhance effective student learning is a modern educational trend [13-16].

2.2. Context-Based Utility Model. Utility function is one kind of multiattribute utility theory which helps users to solve a multicriteria complex problem by utility analysis processing for decision making. Some researchers use utility theory to create various information systems. A decision-making system has been proposed based on utility theory to increase the precision of decisions [17]. A bidirection auction mechanism has been proposed which used utility function to predict user behavior in the auction process [18]. A utility-based model has built for service-oriented computing [6]. In addition, quality is an important consideration in evaluating a problem's solution. Worker feedback on an evaluating process can be represented as a utility model reflecting the satisfaction a worker derives from choosing a solution. The worker provides such a utility model before committing to using a solution [19].

In a comprehensive learning activity, students record learning context information in an e-portfolio platform. Context information in a learning activity provides rich clues for e-learning object selection. Based on the context information of a learning activity, uncovering hidden knowledge is important. Some researches use context information to infer more knowledge to assist users in solving problems. Therefore, context information analysis can quantify all of the influences of the various factors and their relationships to consolidate a utility model. The student's context-based utility model can be applied to monitor context information in order to evaluate the e-learning object's quality. The student will obtain the expected utility value of the issue of interest when choosing an e-learning object. 


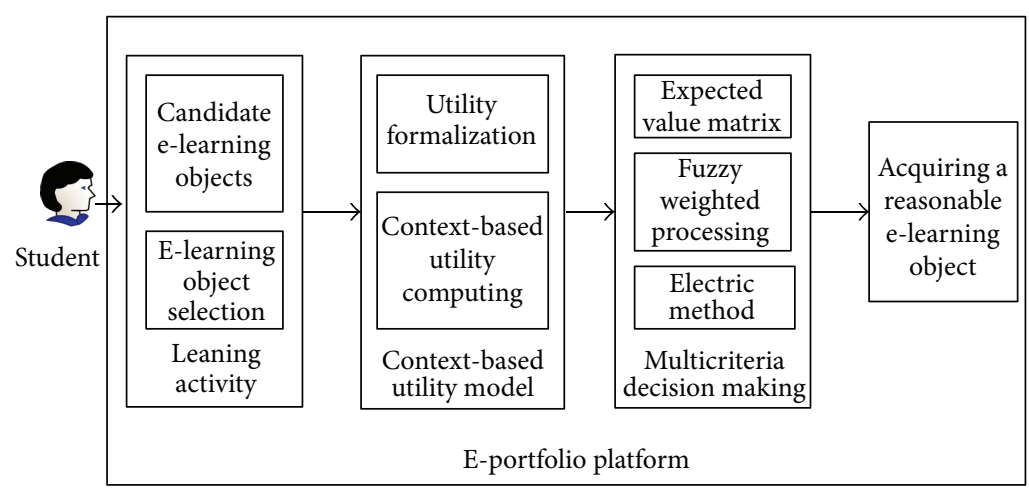

FIGURE 1: A proposed approach for optimal e-learning object acquisition.

2.3. Multicriteria Decision Analysis. Typically, a unique optimal solution does not exist for such problems, so it is necessary to use the preferences of the decision-maker to differentiate between solutions. Multicriteria decision making (MCDM) has played an important role in solving multidimensional and complicated problems $[20,21]$. The purpose is to support decision-makers facing such problems. Therefore, optimal methods are used to enforce multicriteria decision analysis, that is, TOPSIS, VIKOR, and ELECTRE. TOPSIS, VIKOR, and ELECTRE methods have been used to prioritize the production lines [22]. ELECTRE method has been applied with seven criteria for selecting the best one amongst five personnel and identifying the personnel [23]. A selection approach has been proposed for optimized web services compositions based on an ELECTRE method [24]. The ELECTRE methods have been used in optimal problem-solving process for selecting a reasonable solution [25]. The ELECTRE methods have been used in optimal message negotiation process for selecting a reasonable solution in the e-service environment [26]. The ELECTRE methods haves been enforced to the multiattribute decision making under risk with interval [27].

Elimination Et Choice Translating Reality (ELECTRE) is a family of multicriteria decision analysis methods. ELECTRE methods include two main stages. In the first stage, the method constructs the outranking relationships for a comprehensive comparison of each pair of actions. In the second stage, the method elaborates on the recommendations based on the results obtained by an exploitation procedure in the first stage. The nature of the recommendations depends on the problems: choosing, ranking, or sorting [9]. This paper proposes a modified version of the ELECTRE method to determine the optimal selection order of candidate e-learning objects. The selection order is presented to the student to determine which e-learning object is a reasonable e-learning object chosen from candidate e-learning objects.

\section{The Proposed Approach for Optimal E-Learning Object Acquisition}

In this section, a selection approach using a modified version of the ELECTRE method [24-26] for candidate elearning objects is described in terms of a context-based utility computing and fuzzy weighted multicriteria decision analysis. The approach includes the use of e-learning object formalization, context-based utility computing for candidate e-learning objects, and the selection order discovery of candidate e-learning objects, as shown in Figure 1.

3.1. E-Learning Object Formalization. E-Learning object formalization is the essential task of the selection approach. This paper refers to a utility-based reputation model $[6,25,26]$ to formalize e-learning object quality factors in order to reinforce the context-based utility computing.

Let $O=\left\{o_{1}, o_{2}, \ldots, o_{n}\right\}$ denote the set of e-learning object, and $o \in O$. Let OP denote the set of e-learning object providers, $b \in \mathrm{OP}$, and lets function ST: $\mathrm{OP} \rightarrow P(X)$ denote the e-learning objects provided by an e-learning object provider, where $P$ represents the power set operator. Let $S$ denote the set of students in the system, and $s \in S$. Each e-learning object has associated issues of interest, denoted by set $I$, which students are interested in monitoring, and $i \in I$. Function IS represents the set of issues of interest for an e-learning object: IS : $X \rightarrow P(I)$. Function $E^{\mathcal{S}}$ : $\mathrm{O} \times \mathrm{OP} \times I \rightarrow R$ denotes the expectations of a student for the e-learning objects undertaken, where $R$ denotes the real numbers. Notation $v_{o, i}^{s, b}$ represents the expectations of student $s$ on issue $i$ concerning the e-learning object $o$ supplied by provider $b$. In a learning activity, a potential issue of interest could be the quality of the e-learning object. A smart eportfolio platform can develop a context-based utility model which reflects the satisfaction which students gain from choosing an e-learning object.

3.2. Context-Based Utility Computing for Candidate ELearning Objects. After the expectation formalization process of an e-learning object's specific interest issue, a contextbased utility model is developed to represent student satisfaction with the e-learning object acquisition.

The e-learning object's context attributes are key concepts extracted from the learning context of a specific learning activity by Information Retrieval (IR) technology [19]. The extracted context attributes are assumed to be the learning context information. The extracted context attribute, mapped to a specific interest issue $i$ of an e-learning object, is used as a quality factor to build a reference case $S_{j}$. $S_{j}$ is set as 
a desired e-learning object with expected utility values for specific interest issues. The relevant context attributes of thecandidate e-learning object form a comparative case $S_{k}, k=\{1,2, \ldots, m\}$. The similarity value $\operatorname{sim}\left(S_{k}\left(\right.\right.$ ctx_attrb $\left._{x}\right)$, $S_{j}\left(\right.$ ctx_attrb $\left.\left._{x}\right)\right)$ of the two cases, $S_{k}$ and $S_{j}$, is defined in (1), as derived according to their values of context attribute $x$; value $\left(S_{k}\left(\right.\right.$ ctx_attrb $\left.\left._{x}\right)\right)$ denotes the transformed value of context attribute $x$ of $S_{k}$, which is calculated by the discretization process:

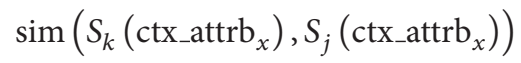

$$
\begin{aligned}
& = \begin{cases}1 & \text { if value }\left(S_{k}\left(\text { ctx_attrb }_{x}\right)\right) \\
& \text { equals value }\left(S_{j}\left(\text { ctx_attrb }_{x}\right)\right) \\
0 & \text { otherwise. }\end{cases}
\end{aligned}
$$

The similarity function used to compute the similarity measured between cases $S_{k}$ and $S_{j}$ is defined in (2)

$$
\delta=\sum_{x=1}^{m} w_{x} \operatorname{sim}\left(S_{k}\left(\mathrm{ctx} \_a t t r b_{x}\right), S_{j}\left(\operatorname{ctx} \_a t t r b_{x}\right)\right),
$$

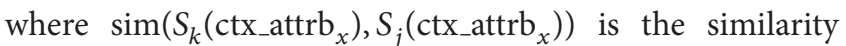
value obtained from the values of context attribute $x$ and $w_{x}$ is the weight given to context attribute $x$. Note that the total of all $w_{x}$ is equal to 1 . If value $\delta$ is closer to 1 , it means that $S_{k}$ and $S_{j}$ have a high correlation. If value $\delta$ is closer to 0 , it means that $S_{k}$ and $S_{j}$ have a low correlation.

Let $\varphi \times v=\xi$; let $U_{o, i}^{s, b}(\xi)$ denote the utility that student $s$ gets by obtaining the actual value $\xi \in R$ on issue $i$ from elearning object $o$ of provider $b$. Utilities are normalized and scaled to $[0,1]$. Based on various issues of interest, selecting the best e-learning object from a large number of e-learning object requires multicriteria decision analysis.

3.3. Determining a Selection Order of Candidate E-Learning Objects. For the second task, this paper proposes a modified version of the ELECTRE method [24-26] to determine the selection order for candidate e-learning objects. If there are $m$ candidate e-learning objects which involve $n$ quality factors, the matrix of expected values can be shown as in (3). The modified version of the ELECTRE method is used to determine the optimal selection order of an e-learning object. The decision matrix $Q$ is a normalization matrix from the elearning object normalization process described in Sections 3.1 and 3.2:

$$
Q=\left[Q_{i j}\right]_{m \times n}=\left[\begin{array}{ccc}
U_{1,1}^{s, b}\left(\xi_{1,1}^{s, b}\right) & \cdots & U_{1, n}^{s, b}\left(\xi_{1, n}^{s, b}\right) \\
\vdots & \ddots & \vdots \\
U_{m, 1}^{s, b}\left(\xi_{m, 1}^{s, b}\right) & \cdots & U_{m, n}^{s, b}\left(\xi_{m, n}^{s, b}\right)
\end{array}\right]
$$

To calculate the weighted normalization decision matrix, a weight for each quality factor must be set to form a weighted matrix $(W)$. The weighted matrix is dealt with by fuzzy method: center average defuzzifier (CAD). For a weight value set $U_{w}=\left\{w_{1}, w_{2}, \ldots, w_{n}\right\}, w$ is the weight value of a specific e-learning object utility $U_{o, i}^{s, b}(\xi)$ and $n$ is the total count.
Equations (4) get the fuzzy fragment $F_{s}$ value, $\overline{y^{X}}$ is the center of $x$ fuzzy sets, and $z_{x}$ is its height:

$$
\begin{gathered}
\frac{\sum_{k=1}^{n} w_{k}}{n}=F_{s}, \\
y^{*}=\frac{\sum_{x=1}^{m} \overline{y^{x}} z_{x}}{\sum_{x=1}^{m} z_{x}} .
\end{gathered}
$$

The multiplication of a normalization matrix $Q$ by a weighted matrix $W$ then obtains the weighted normalization decision matrix $V(V=Q W)$, as

$$
V=\left[v_{i j}\right]_{m \times n}=\left[Q_{i j}\right]_{m \times n} \cdot\left[W_{i j}\right]_{n \times n} \cdot
$$

Compare arbitrarily different row $i$ and row $j$ in the weighted normalization decision matrix $V$ to verify the concordance and discordance set. If value $v$ of row $i$ is higher than value $v$ of row $j$, the component $k$ can be classified as the concordance set $C_{i j}\left(C_{i j}=\left\{k \mid v_{i k} \geq v_{j k}\right\}\right)$, or the discordance set $D_{i j}\left(D_{i j}=\left\{k \mid v_{i k} \leq v_{j k}\right\}\right)$. The sum of each component's weight forms a concordance matrix $C$, as

$$
C=\left[c_{i j}\right]_{m \times m}, \quad c_{i j}=\frac{\sum_{k \in c_{i j}} w_{k}}{\sum_{k=1}^{n} w_{k}}
$$

A discordance matrix can be presented as $D=\left[d_{i j}\right]$; we use a formula to get the discordance matrix. $S$ is the set including all quality factors, $S=\{1,2, \ldots, n\}$, as

$$
D=\left[d_{i j}\right]_{m \times m}, \quad d_{i j}=\frac{\max _{k \in D_{i j}}\left\{\left|v_{i k}-v_{j k}\right|\right\}}{\max _{k \in S}\left\{\left|v_{i k}-v_{j k}\right|\right\}} .
$$

The reverse complementary value is used to modify $D$ to obtain the modified discordance matrix $D^{\prime}\left(D^{\prime}=1-D\right)$. To show the large component value of the candidate e-learning object, when the expected value is larger, we combine each component $C_{i j}$ of the concordance set with the modified discordance matrix in order to calculate the production and get the modified total matrix $A\left(A=C \circ D^{\prime}\right.$, Hadamard product of $C$ and $D^{\prime}$ ). We obtain the maximum value $a_{j}$ of each column from the modified total matrix. The purpose is to determine the modified superiority matrix. To make a reasonable e-learning object, we have to rank $a_{j}$ from small to large: $a_{1}, a_{2}, \ldots, a_{m}$. The threshold $\bar{a}$ is set behind the smallest value $a_{1}^{\prime}$ and the next smallest value $a_{2}^{\prime}$. If the value $a_{i j}$ is smaller than threshold $\bar{a}$, it is replaced as 0 or 1 . We then get the modified total superiority matrix, as

$$
E^{\prime}=\left[e_{i j}^{\prime}\right], \quad e_{i j}^{\prime}= \begin{cases}1, & a_{i j} \geq \bar{a} \\ 0, & a_{i j}<\bar{a}\end{cases}
$$

Finally, the matrix $E^{\prime}$ indicates that e-learning object $i$ is better than e-learning object $j$. We can eliminate e-learning object $j$ and show it as $A_{i} \rightarrow A_{j}$.

The relationships between the quality factors of the candidate e-learning objects as well as the optimal selection order for all candidate e-learning objects are obtained. The candidate e-learning object is the solution provided by the elearning objects provider. The student can follow the selection order to obtain a reasonable e-learning object. 
TABLE 1: Quality factors of e-learning objects of a specific learning activity.

\begin{tabular}{lccc}
\hline & Introducing & Practicing & Testing \\
\hline E-learning object A & High & Middle & Low \\
E-learning object B & Middle & Low & High \\
E-learning object C & Low & High & Middle \\
\hline
\end{tabular}

TABLE 2: Transformed quality factors of e-learning objects.

\begin{tabular}{lccc}
\hline & Introducing & Practicing & Testing \\
\hline E-learning object A & 0.50 & 0.30 & 0.20 \\
E-learning object B & 0.30 & 0.25 & 0.45 \\
E-learning object C & 0.20 & 0.45 & 0.35 \\
\hline
\end{tabular}

\section{A Use Case to Illustrate the Steps of an Optimal Selection Approach}

This section presents the use of a specific case to illustrate the steps of the proposed optimal selection approach.

4.1. E-Learning Objects Formalization and Context-Based Utility Model. When a student engages in a specific learning activity, various suppliers provide e-learning objects. We use e-learning object formalization and a context-based utility model to precompute a student's expected list of supplied elearning object quality factors and to facilitate a multicriteria decision analysis to discover an optimal selection order for candidate e-learning objects.

First, the e-learning object formalization process identifies the student, e-learning object, and e-learning object providers. Then, the student can choose the indicators (quality factors) of the current learning activity. We use a practical project learning activity as a simple use case process. The student sets Introduce, Practice, and Testing as the quality factors for the practical project learning activity. Then, the relevant values of the quality factors and e-learning objects are recorded in a table, as shown in Table 1 . The e-learning objects $\mathrm{A}, \mathrm{B}$, and $\mathrm{C}$ are used as the candidate e-learning objects for the demonstration of the proposed method in these experiments. For example, e-learning object A sets the quality factor, the practical project learning activity, where the Introducing degree is high, Practicing is middle, and Testing is evaluated as low.

After the e-learning object formalization process, a context-based utility model is developed to represent student satisfaction with the e-learning object acquisition. Each quality factor is normalized, and scaled to $[0,1]$. Table 1 is then transformed into Table 2.

4.2. The Selection Order Discovery of Candidate E-Learning Objects. This work proposes a modified version of the ELECTRE method [24-26] to discover the optimal selection order of candidate e-learning objects for a specific learning activity.
The decision matrix $Q$ of expected values can be shown as follows:

$$
Q=\left[\begin{array}{lll}
0.50 & 0.30 & 0.20 \\
0.30 & 0.25 & 0.45 \\
0.20 & 0.45 & 0.35
\end{array}\right]
$$

The fuzzy weighted matrix $(W)$ for each quality factor is shown as follows:

$$
W=\left[\begin{array}{ccc}
0.28 & 0 & 0 \\
0 & 0.40 & 0 \\
0 & 0 & 0.32
\end{array}\right]
$$

The multiplication of a normalization matrix $Q$ and a weighted matrix $W$ produces the weighted normalization decision matrix $V(V=Q \cdot W)$, as follows:

$$
\begin{aligned}
V & =Q \cdot W=\left[\begin{array}{lll}
0.50 & 0.30 & 0.20 \\
0.30 & 0.25 & 0.45 \\
0.20 & 0.45 & 0.35
\end{array}\right] \cdot\left[\begin{array}{ccc}
0.28 & 0 & 0 \\
0 & 0.40 & 0 \\
0 & 0 & 0.32
\end{array}\right] \\
& =\left[\begin{array}{ccc}
0.14 & 0.12 & 0.064 \\
0.084 & 0.10 & 0.144 \\
0.056 & 0.18 & 0.112
\end{array}\right] .
\end{aligned}
$$

The concordance set $C_{i j}$ or the discordance set $D_{i j}$ is shown as follows:

$$
\begin{array}{ll}
C_{12}=\{1,2\}, & D_{12}=\{3\}, \quad C_{13}=\{1\}, \\
D_{13}=\{2,3\}, \quad C_{21}=\{3\}, & D_{21}=\{1,2\}, \\
C_{23}=\{1,3\}, \quad D_{23}=\{2\}, & C_{31}=\{2,3\}, \\
D_{31}=\{1\}, \quad C_{32}=\{2\}, & D_{32}=\{1,3\} .
\end{array}
$$

The sum of each component's weight forms a concordance matrix $C$ :

$$
\begin{gathered}
C_{13}=\frac{\sum_{k \in c_{13}} w_{k}}{\sum_{k=1}^{3} w_{k}}=\frac{W_{1}}{W_{1}+W_{2}+W_{3}}=0.28, \\
C=\left[\begin{array}{ccc}
\cdots & 0.68 & 0.28 \\
0.32 & \cdots & 0.60 \\
0.72 & 0.40 & \cdots
\end{array}\right] .
\end{gathered}
$$

A discordance matrix can be presented as $D$ :

$$
\begin{aligned}
& D_{13}= \frac{\max _{k \in D_{13}}\left\{\left|v_{1 k}-v_{3 k}\right|\right\}}{\max _{k \in S}\left\{\left|v_{1 k}-v_{3 k}\right|\right\}} \\
&= \frac{\max \{0.052\}}{\max \{0.07,0.052,0.0384\}}=0.74 \\
& D=\left[\begin{array}{ccc}
\cdots & 1 & 0.71 \\
0.70 & \cdots & 1 \\
0.71 & 0.4 & \cdots
\end{array}\right] .
\end{aligned}
$$

A modified discordance matrix can be presented as $D^{\prime}$ :

$$
D^{\prime}=1-D=\left[\begin{array}{ccc}
\cdots & 0 & 0.29 \\
0.3 & \ldots & 0 \\
0.29 & 0.6 & \ldots
\end{array}\right]
$$




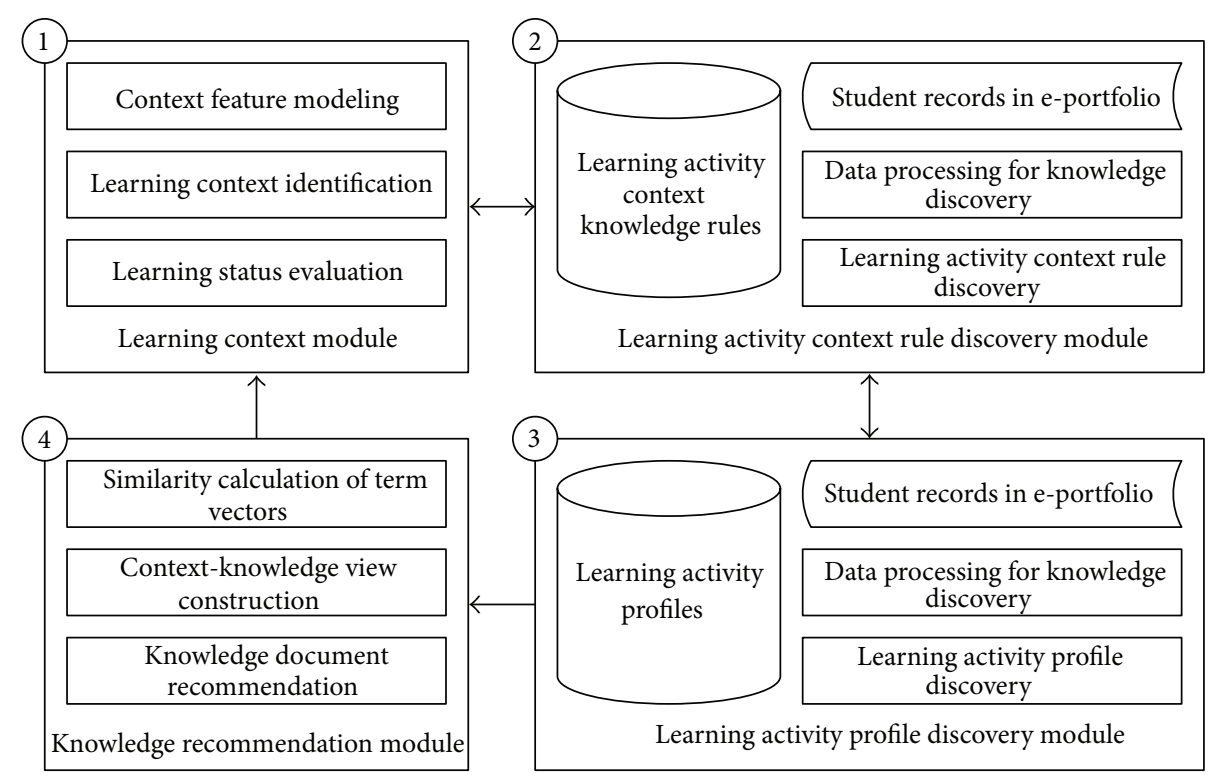

FIGURE 2: The prototype e-portfolio platform [13].

A modified total matrix can be presented as $A$ :

$$
A=C \circ D^{\prime}=\left[\begin{array}{ccc}
\cdots & 0 & 0.081 \\
0.096 & \cdots & 0 \\
0.209 & 0.24 & \cdots
\end{array}\right]
$$

A modified total superiority matrix is shown as $E^{\prime}$ :

$$
E^{\prime}=\left[\begin{array}{ccc}
\cdots & 0 & 0 \\
1 & \cdots & 0 \\
1 & 1 & \cdots
\end{array}\right]
$$

Finally, we get the optimal selection order for all candidate elearning objects. The experiment results show that e-learning object $B$ is better than e-learning object $A\left(e_{21}^{\prime}=1, A_{2} \rightarrow\right.$ $\left.A_{1}\right)$; e-learning object $C$ is better than e-learning object $A\left(e_{31}^{\prime}=1, A_{3} \rightarrow A_{1}\right)$; and e-learning object $C$ is better than e-learning object $B\left(e_{32}^{\prime}=1, A_{3} \rightarrow A_{2}\right)$. The student can follow the optimal selection order $\left(A_{3}, A_{2}, A_{1}\right)$ to obtain a reasonable e-learning object.

\section{Experiments and Discussions}

This section demonstrates the prototype e-portfolio platform and presents the experiment results and relevant discussion.

5.1. The Prototype E-Portfolio Platform. The prototype eportfolio platform [13] is shown in Figure 2. The system framework comprises the learning context, learning activity context rule discovery, learning activity profile discovery, and knowledge recommendation modules. The learning context module gathered run-time information of a student's learning activities, such as learning features and context information. According to the identified learning context and contextknowledge view, based on the knowledge recommendation module, the system evaluated the student's learning status and recommended relevant knowledge documents. The specific learning context, including learning activities and corresponding knowledge documents, was recorded in the records of the e-portfolio.

We used the log file in a prototype e-portfolio platform [13] as a source of analysis data. For specific learning activities, relevant e-learning objects accessed by students are recorded in the prototype e-portfolio platform log. Information Retrieval (IR) technology is used to extract the key concepts of e-learning objects based on a learning context of a learning activity. The extracted key concepts form a learning profile, which is used to model the information needs of the students. We assume that a generic learning activity is specified by experts. Different students may find different elearning objects for the same learning activity, according to their abilities. The prototype e-portfolio platform log records historical learning context instances.

5.2. Experiment. The experiments on the practical project learning activity in a university [13] are shown in this section. The prototype e-portfolio platform log was used as a source of analysis data. This paper used Information Retrieval techniques to analyze the data, and 3,164 relevant data records were obtained from the practical project learning activity. The retrieved data records involve 8 learning activities, 41 students, and 813 e-learning objects. In this research, four domain experts assisted in carrying out the experiments and the evaluation of the results. The experiment results from this paper's method show that precision is $37.94 \%(96 / 253)$ and recall is $45.71 \%(96 / 210)$. The experiment results of the method proposed in the research [13] show that precision is $31.23 \%(79 / 253)$ and recall is $37.62 \%(79 / 210)$. The selection method used in this work seems to be more effective than the method proposed by [13].

5.3. Discussion. The lower values of precision and recall indicate that current e-learning objects' quality is not good 
enough to support the practical project learning activity. In the experiment process and results analysis, it was found that the practical project learning activity is a comprehensive learning activity. Students fetch various official and unofficial e-learning objects to explore an open topic and find a comprehensive solution, that is, database theory, system programming, network protocol, project management, and so forth. The e-learning objects provided by an e-portfolio platform seem to be insufficient to assist effective student learning. In addition, the e-learning object's actual utility values from the context-based utility model and the weight value in multicriteria decision analysis tasks are the critical factors influencing the experiment results. For example, the normalization utility values and weight values are indistinguishable. This prevents the method from identifying a reasonable e-learning object for the e-learning object determination. This study checks and adjusts the normalization utility values and uses a fuzzy weight model to enhance the distinguishing ability. User feedback influences how the quality factor is decided. The quality factor is the critical item for the context-based utility model and the multicriteria decision analysis processing.

\section{Conclusions}

To assist student learning in a modern e-portfolio platform, this work proposed an optimal selection approach determining a reasonable e-learning object from various candidate elearning objects. Each e-learning object has a formalization process. An Information Retrieval technique extracts and analyzes key concepts from the student's previous learning contexts. A context-based utility model computes the expected utility values of various e-learning objects, based on the extracted key concepts. The expected utility values of elearning objects are used in a multicriteria decision analysis to determine the optimal selection order of the candidate e-learning objects. The selection order is presented as the decision-making knowledge to assist a student in acquiring a reasonable e-learning object.

The experimental results demonstrate the effectiveness of providing decision-making knowledge to help students learn. The main contribution of this work is the demonstration of an effective e-learning object selection method that is easy to implement into an e-portfolio platform, making it smarter. Future studies can pay more attention to designing interactive feedback mechanisms. Feedback can enable the e-portfolio platform to perform intelligent turning and learning in order to improve the proposed approach and make it more robust. Furthermore, the property of a heterogeneous learning environment should be considered in order to provide context-aware computing and ubiquitous learning support.

\section{Acknowledgment}

This research was supported in part by the National Science Council of Taiwan (Republic of China) with an NSC Grant 102-2410-H-025-017.

\section{References}

[1] P. S. Tsai, C. C. Tsai, and G. H. Hwang, "College students' conceptions of context-aware ubiquitous learning: a phenomenographic analysis," Internet and Higher Education, vol. 14, no. 3, pp. 137-141, 2011.

[2] C. Diehm, "From worn-out to web-based: better student portfolios," Phi Delta Kappan, vol. 85, no. 10, pp. 792-794, 2004.

[3] C. C. Chen and T. C. Huang, "Learning in a u-museum: developing a context-aware ubiquitous learning environment," Computers and Education, vol. 59, no. 3, pp. 873-883, 2012.

[4] M. Hammond-Todd, N. Feliciano, and W. Gallagher, "MM-e at the museum: a mobile memory e-portfolio platform application for young children in diverse museum environments," in Proceedings of the World Conference on Educational Multimedia, Hypermedia and Telecommunications, T. Amiel and B. Wilson, Eds., pp. 601-604, Denver, Colo, USA, 2012.

[5] Y. M. Huang and T. T. Wu, "A systematic approach for learner group composition utilizing u-learning portfolio," Educational Technology and Society, vol. 14, no. 3, pp. 102-117, 2011.

[6] G. C. Silaghi, A. E. Arenas, and L. M. Silva, "A utility-based reputation model for service-oriented computing," in Towards Next Generation Grids, pp. 63-72, Springer, New York, NY, USA, 2007.

[7] A. K. Dey, "Understanding and using context," Journal of Personal and Ubiquitous Computing, vol. 5, no. 1, pp. 4-7, 2001.

[8] H. Ogata, M. M. Li, B. Hou, and N. Uosaki, "Context-aware support for language learning using ubiquitous learning logs," in Proceedings of the International Conference on Technology for Education/758: Software Engineering and Applications, ACTA Press, Dallas, Tex, USA, December 2011.

[9] L. Antonieta and S. S. Vasco, "Multi criteria decision making models: an overview on electre methods," Working Paper, Universidade Portucalense, Centro de Investigaço em Gesto e Economia (CIGE), 2011.

[10] R. J. Beck, N. L. Livne, and S. L. Bear, "Teacher's self-assessment of the effects of formative and summative electronic portfolios on professional development," European Journal of Teacher Education, vol. 28, no. 3, pp. 221-244, 2005.

[11] M. E. Torras and R. Mayordomo, "Teaching presence and regulation in an electronic portfolio," Computers in Human Behavior, vol. 27, no. 6, pp. 2284-2291, 2011.

[12] M. M. Kwan and P. Balasubramanian, "KnowledgeScope: managing knowledge in context," Decision Support Systems, vol. 35, no. 4, pp. 467-486, 2003.

[13] C. K. Ke and M. Y. Wu, "Adaptive support for student learning in an e-portfolio platform by knowledge discovery and casebased reasoning," Journal of Software, vol. 5, no. 12, pp. 1355$1362,2010$.

[14] D. T. Ku and W. C. Chang, "A design framework for a conceptual multi-dimensional learning assessment system," International Journal of Digital Content Technology and Its Applications, vol. 6, no. 6, pp. 228-238, 2012.

[15] D. T. Ku and W. C. Chang, "uFolio: a conceptual design framework for a learning platform and assessment system," in Proceedings of the 7th IEEE International Conference on Networked Computing and Advanced Information Management (NCM '11), pp. 358-363, Gyeongju, Republic of Korea, June 2011.

[16] T. C. Yang, H. C. Chiang, and J. H. Yang, "Creating e-portfolio in U-learning environment: a framework of could-based eportfolio service," in Proceedings of the 7th IEEE International 
Conference on Wireless, Mobile and Ubiquitous Technology in Education, pp. 292-295, Takamatsu, Japan, March 2012.

[17] I. T. Yang, "Utility-based decision support system for schedule optimization," Decision Support Systems, vol. 44, no. 3, pp. 595605, 2008.

[18] J. H. Choi, H. Ahn, and I. Han, "Utility-based double auction mechanism using genetic algorithms," Expert Systems with Applications, vol. 34, no. 1, pp. 150-158, 2008.

[19] C. K. Ke and D. R. Liu, "Context-based knowledge support for problem-solving by rule-inference and case-based reasoning," International Journal of Innovative Computing, Information and Control, vol. 7, no. 7, pp. 3615-3631, 2011.

[20] D. F. Li, "A ratio ranking method of triangular intuitionistic fuzzy numbers and its application to MADM problems," Computers \& Mathematics with Applications, vol. 60, no. 6, pp. 15571570, 2010.

[21] G. W. Wei, "Gray relational analysis method for intuitionistic fuzzy multiple attribute decision making," Expert Systems with Applications, vol. 38, no. 9, pp. 11671-11677, 2011.

[22] E. Pourjavad and H. Shirouyehzad, "A MCDM approach for prioritizing production lines: a case study," International Journal of Business and Management, vol. 6, no. 10, pp. 221-229, 2011.

[23] A. R. Afshari, M. Mojahed, R. M. Yusuff, T. S. Hong, and M. Y. Ismail, "Personnel selection using ELECTRE," Journal of Applied Sciences, vol. 10, no. 23, pp. 3068-3075, 2010.

[24] Y. L. Chi, C. W. Lee, and C. Y. Chen, "A selection approach for optimized web services compositions," Electronic Commerce Studies, vol. 2, no. 3, pp. 297-314, 2004.

[25] C. K. Ke and M. Y. Wu, "A selection approach for optimized problem-solving process by grey relational utility model and multi-criteria decision analysis," Mathematical Problems in Engineering, vol. 2012, Article ID 293137, 14 pages, 2012.

[26] C. K. Ke and Y. L. Chen, "A message negotiation approach to eservices by utility function and multi-criteria decision analysis," Computers and Mathematics with Applications, vol. 64, no. 5, pp. 1056-1064, 2012.

[27] P. Liu, F. Jin, X. Zhang, Y. Su, and M. Wang, "Research on the multi-attribute decision-making under risk with interval probability based on prospect theory and the uncertain linguistic variables," Knowledge-Based Systems, vol. 24, no. 4, pp. 554-561, 2011. 


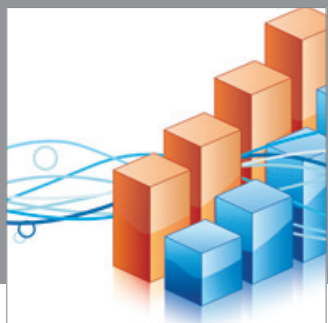

Advances in

Operations Research

mansans

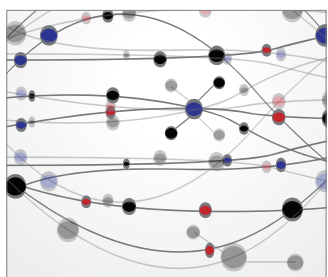

The Scientific World Journal
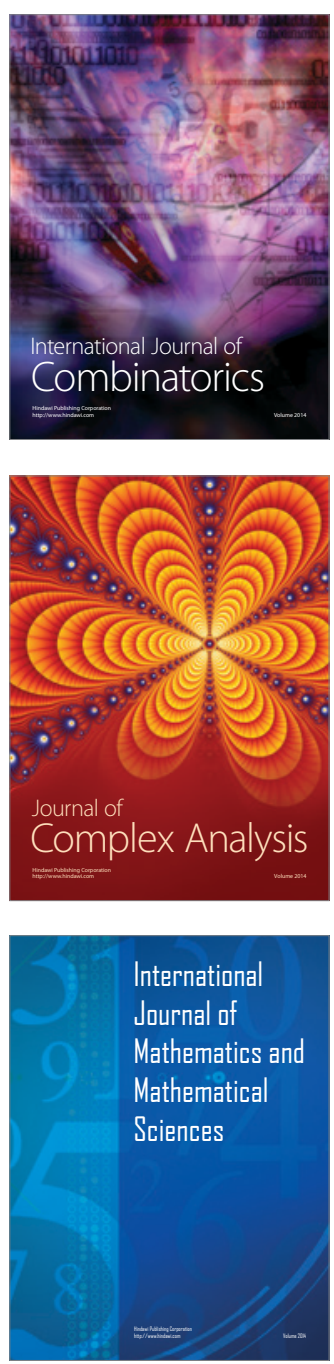
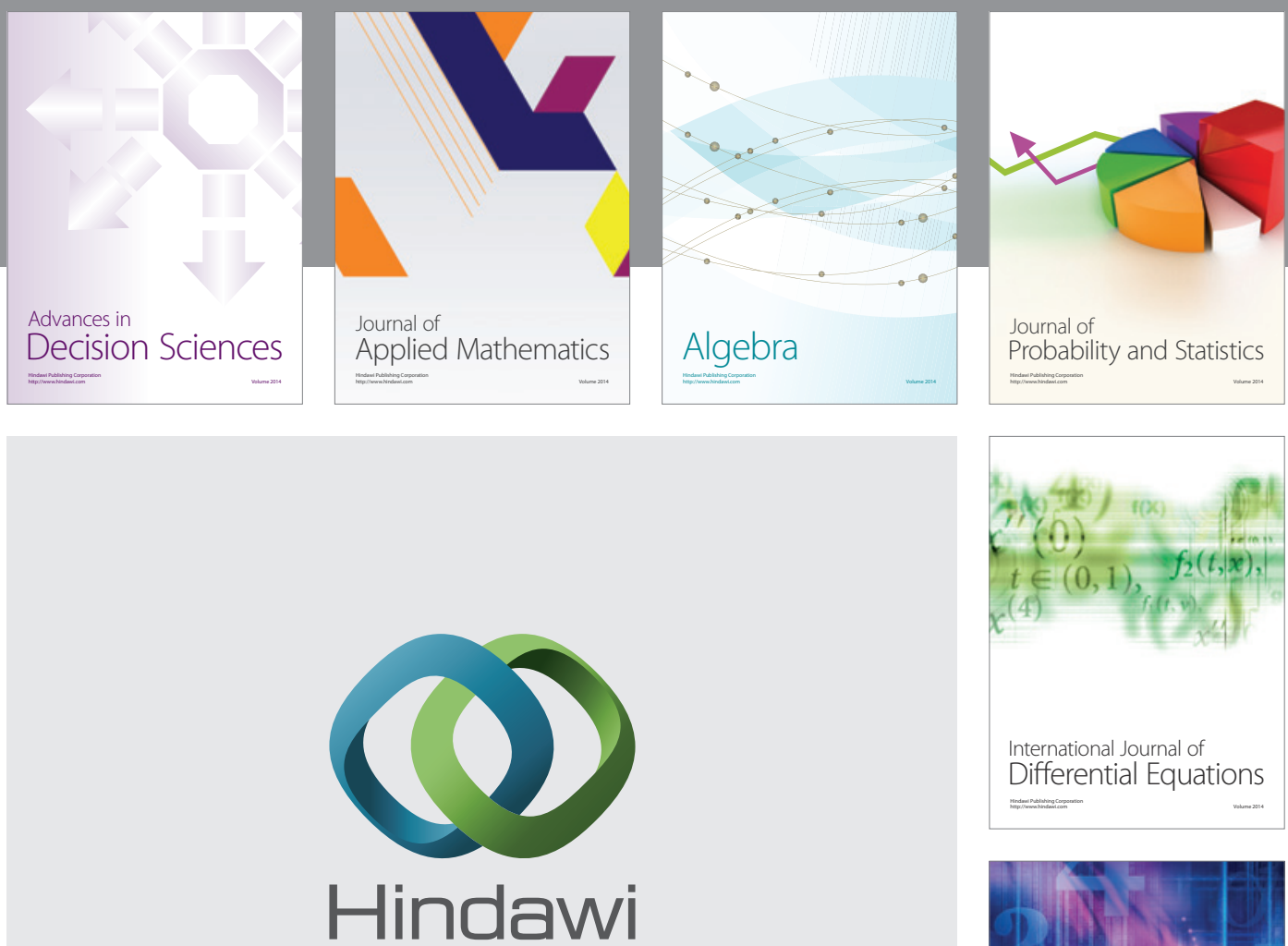

Submit your manuscripts at http://www.hindawi.com
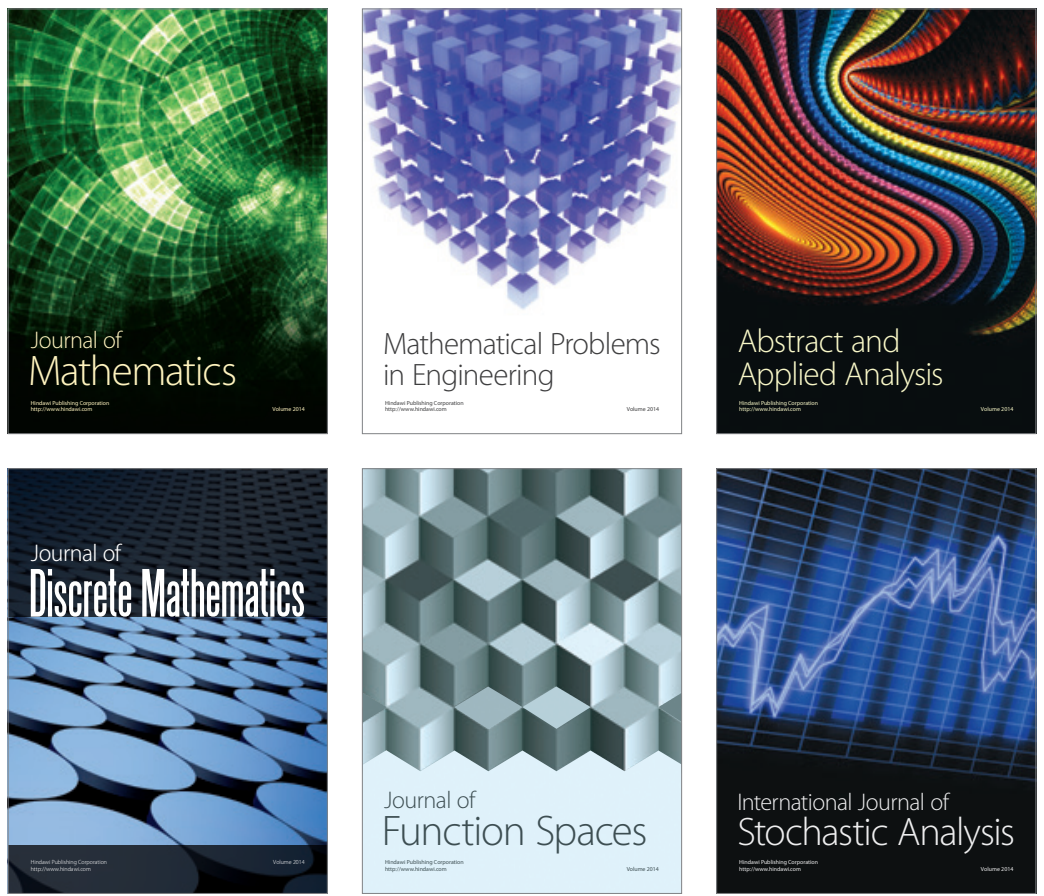

Journal of

Function Spaces

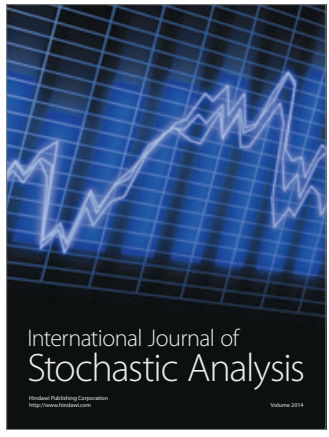

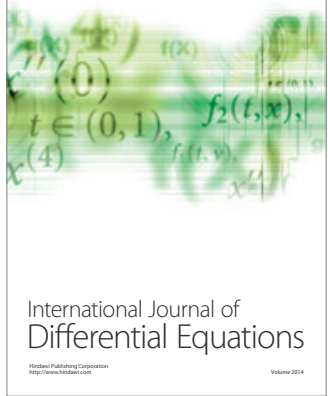
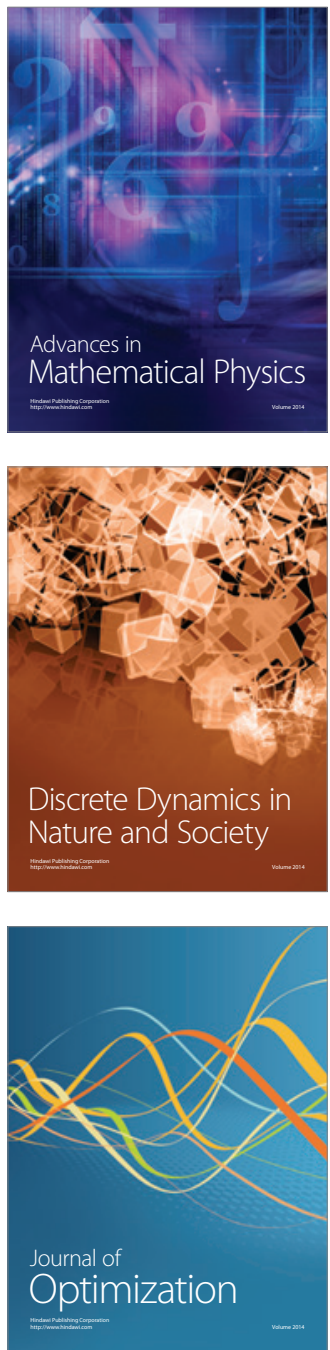